that of an intrigue, which probably led to the duel which cost him his life. The duel took place on the early morning of May 30, 1832, and he died next day in the Hôpital Cochin. His complete works fill only sixty-one small pages, but a French geometer, publishing a large volume some forty years after Galois' death, declared that it was simply a commentary on the latter's discoveries.

\section{Faraday and Benzene}

The Royal Institution audience at the Friday evening discourse on May 20 had a stimulating experience when Prof. Henry E. Armstrong addressed them with "Faraday at the Sign of the Hexagon" as his subject; "Coal Colour and Constitution" was the alleged theme of the evening, but this venerable Lewis Carroll of chemistry allowed himself freely to be led only by the spirit of the moment. With the lecture room decorated like an Eastern bazaar, with fabrics of every pattern and hue, the 'lecturer' was evidently content to appear as a benevolent 'high priest of colour', wearing himself as regalia a waistcoat of the genuine nursery sky blue and pink. The ordinary symbols of the orthodox chemist were discarded for this occasion, " as people won't take the trouble to understand their meaning"; so straight-chains and ring compounds were replaced by the backbone of a mackerel and by a whiting with tail in mouth ready for the kitchen ; also buttons on safety-pins deputised for the unwieldy formulæ of the dyes chemist, all used to illustrate the genealogy of benzene, that " pallid infant of the sober Faraday", "taken as mistress by Hofmann", with progeny the "gentle Ani-line" and her numerous offspring whose " hectic and chromatic careers" were vividly described. Nor must Miss Hook of Holland be forgotten, who left her seat by the chairman to display her famous many-hued petticoats, as illustrations of the dyes which the chemists' control of colour has produced from the same base.

\section{Statue to Trevithick}

ON May 17, at Camborne, Prince George unveiled a statue of the eminent Cornish engineer, Richard Trevithick, which has been erected in front of the Free Library. Trevithick was born in the neighbouring parish of Illogan in 1771, but soon after his birth his parents removed to a cottage in Camborne, which is now being preserved as a memorial, and after his marriage Trevithick himself had a house and workshop in Fore Street. Like his father, he was a mine engineer, but he will always be remembered as a pioneer in the use of high pressure steam and of the locomotive. The statue which has been erected depicts him holding a model of his first road locomotive. Previous to the unveiling of the statue, Prince George had attended a luncheon at the Camborne School of Mines, at which there were representatives of the county of Cornwall, various engineering and scientific societies, and the railways. The project for raising a memorial to Trevithick was started in 1911, but owing to the War and other causes its completion has been much delayed. The other memorials to Trevithick include a window in Westminster Abbey, a scholar- ship at the University of Manchester, the Trevithick premium of the Institution of Civil Engineers, and the tablet in Dartford Parish Church, in the grounds of which he was buried in April 1833.

\section{British Broadcasting}

In a thoughtful address at the Royal Institution on May 13, Sir John Reith indicated some of the reflections and conclusions forced upon him by his ten years' experience of broadcasting. These bore mainly upon the influence of the peculiar constitution of the British Broadcasting Corporation upon its effectiveness and success. The rationalised nationalisation of that body gives it freedom from the cramping and cumbersome system of a government department, while yet retaining a certain degree of public control. It can proceed to carry out the terms of its commission as unhampered as any private enterprise, but the objections to private enterprise are eliminated by the public control of matters of major policy. Monopoly, Sir John regards as an essential of the efficient national system not only on economic and administrative grounds, but also because competition in broadcasting reduces programmes to the level of the greatest demand, and that would have cut out much of the service to music and education which the B.B.C. has been able to render. Finally, personal direction by an individual aware of his responsibility and having the courage of his convictions, leads, as no form of government depending upon the suffrages of electors can lead, to decisive and consistent action.

UNDER such a regime, Sir John Reith foresees a great future for broadcasting. It is not without significance that so many other countries have, with adaptation to local needs, copied the work and form of the B.B.C. Britain appears to have sensed in this respect a need that was common to all nations belonging to the European culture, perhaps because through this system democracy may at last be able to come to its own. Nationally, he said, this obtains because the peculiar nature of the medium imposes sincerity and moderation on speaker and thoughtfulness on hearer, and because those who have something real to contribute to society are brought into direct contact with, not the masses, but the individual members of that society. Internationally, it obtains because ether waves do not stop at frontiers, so that the foreign listener must come, if not to agree with, at least to respect, points of view different from his own, presented to him with the sincerity that carries force and without the violence that provokes it.

\section{The Expanding Universe}

IN his Ludwig Mond lecture, delivered at Manchester on May 9, on the subject of "The Expanding Universe ", Sir James Jeans began with a review of the system of galaxies, our knowledge of which has been greatly extended by recent work with the 100 inch reflector at Mt. Wilson. From these results, he concludes that some two million nebulæ lie within a distance of $140,000,000$ light-years - a sphere of observation which bears the same ratio to the whole 